DOI: http://dx.doi.org/10.22201/iie.18703062e.2001.78.2007

\author{
CARLOSCHANFÓN OLMOS†
}

FACULTAD DE ARQUITECTURA, UNAM

\title{
El PlanodeSankt Gallen
}

L Documento conocido como "Plano de Sankt Gallen"i es probablemente el testimonio más valioso y más antiguo sobre la arquitectura monacal que nos ha legado la Edad M edia. Se trata de un dibujo de tinta, ejecutado sobre una pieza de pergamino formada por cinco partes hilvanadas para al canzar las dimensiones de iı2 por $77 \mathrm{~cm}$ (figura I).

El documento data del primer tercio del siglo ix y está relacionado con la reforma monacal promovida por el abad san Benito de Aniano (750-82I), discutida en dos sínodos, celebrados en 8I6 y 8ı7 en Aquisgrán y respaldada por la autoridad imperial. La reforma implicó, en términos generales, la adopción de la regla de san Benito de Nursia por todos los monasterios en los territorios del Imperio.

I. Supe de la existencia del Plano de Sankt G allen en la década de los años sesenta, cuando adquirí el Diccionario razonado de Viollet-le-D uc y leí el artículo "Architecture M onastique" (t. I, pp. 24I-327). Preocupado por aquellos años en demostrar lo absurdo del concepto de fortificación aplicado a nuestros monasterios mendicantes, encontré ahí importantes conceptos sobre la arquitectura monacal medieval. En i97i conocí a X avier M oyssén, siempre interesado en el fenómeno arquitectónico mexicano, aunque ya entonces más dedicado a la pintura. De inmediato hicimos una gran amistad, que con los años sólo se acrecentó. Pronto nuestro tema de conversación se centró, en varias ocasiones, en los monasterios mexicanos y en el Plano de Sankt Gallen como su antecedente gráfico más remoto. Q uiso el destino que, en los últimos días de abril de 20or, visitara yo por segunda vez el famoso monasterio y su biblioteca en la pequeña ciudad suiza de Sankt Gallen. Al observar una reproducción del plano expuesta en una vitrina de la Stiftsbibliothek, no pude menos que recordar con cariño aquellas pláticas con Xavier, unos treinta años atrás. N unca pensé que unas semanas después nos abandonaría. $\checkmark$ ayan estos párrafos en modesto homenaje a su memoria. 
DOI: http://dx.doi.org/10.22201/iie.18703062e.2001.78.2007

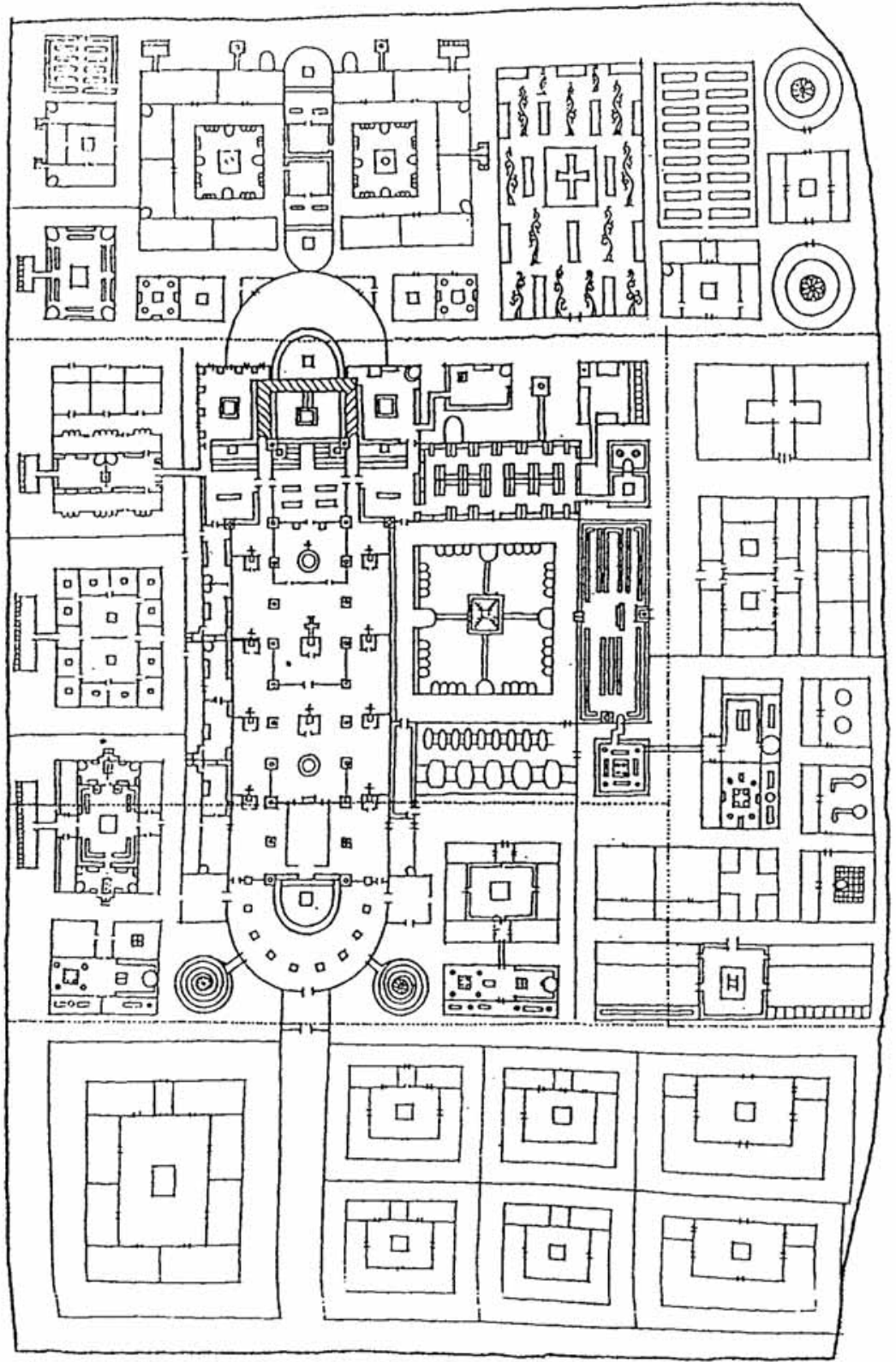

Figura i. Plano de Sankt G allen, elaborado en el siglo ix. 
Tres siglos después de haber sido dibujado el Plano, el reverso del documento fue utilizado por un amanuense que ahí transcribió una versión de la vida de san M artín de Tours. Ésta fue probablemente la circunstancia que permitió la conservación de este verdadero tesoro medieval. En efecto, olvidada ya la razón fundamental de su factura, el documento fue doblado en dieciséis partes - hasta obtener el tamaño aproximado de un libro- y conservado en la biblioteca del monasterio de Sankt Gallen, bajo la creencia de que era la vida de san M artín de Tours (316-397) - famoso obispo, predicador e iniciador de la vida religiosa en las Galias- ilustrada con un croquis de su monasterio.

Fue el rector de la Universidad de Ingolstadt, el profesor $\mathrm{H}$ enricus Canisius, en I604, quien dio la primera noticia sobre el documento en sus Spigrammata. Un poco más tarde, el benedictino Jean Mabillon, en I683, inició los estudios analíticos e interpretativos que desde entonces ha inspirado el documento y que hoy constituyen ya una muy rica, voluminosa y compleja bibliografía. ${ }^{2}$

La dedicatoria del Plano, que se encuentra cercana al ángulo superior derecho del documento, encierra la clave de su origen, que sigue siendo motivo de diversas opiniones entre los investigadores que la han analizado. Es claro, sin embargo, que una alta autoridad eclesiástica y monacal envió el documento a G ozberto († 837), abad de Sankt Gallen (816-836). Es patente, en la redacción de la nota, el esfuerzo del remitente para no herir al destinatario, evitando que interprete el envío como un acto autoritario, y lo vea más como un gesto amistoso. La dedicatoria dice a la letra:

$\mathrm{H} æ$ tibi dulcissime fili Cozberte de posicione officinarum paucis exemplata direxi quibus sollertiam exerceas tua meamque $\cdot$ devotione utcumque $\cdot$ cognoscas - qua tuæ bonævoluntati satisfacere me segnem non inveniri confido · N e suspiceris autem me hæc ideo elaborasse - quod nos putemus nostris indigere magisteriis - sed potius ob amore dei tibi soli pscrutinanda pinxisse amicabili fraternitatis intuitu crede · Vale in Cro semper memor nostri · amen

2. Carol H eitz, W erner Vogler y François H eber-Suffrin, Le Rayonnement spirituel et culturel de l'abbaye de Saint-Gall, Centre de Recherches Sur I'Antiquité Tardive et le $\mathrm{H}$ aut M oyen Âge, U niversité de Paris X-N anterre, 2000, p. 5. 
DOI: http://dx.doi.org/10.22201/iie.18703062e.2001.78.2007

Para ti, queridísimo hijo G ozberto, he trazado la copia, con pocas anotaciones, de la posición de dependencias [monacales] con las cuales utilices tu habilidad al tiempo que reconozcas mi devoción, de modo que confío que no me encuentres lento en satisfacer tu buena voluntad. $\mathrm{No}$ creas que he hecho esto por creer que necesitas consejos, sino más bien lo he dibujado por amor de Dios, mirando con amigable fraternidad que lo examines tú solo. Q ue te conserves bien en Cristo, que siempre nos recuerda. Amén. 3

M ientras es claro que el Plano fue elaborado específicamente para obsequiarlo al abad Gozberto, queda la incógnita sobre quién es el que lo envió. Los candidatos se han sucedido a través de los años, a partir de la atribución hecha por Dom Mabillon, en I704, proponiendo al monje Eguinardo, asesor y biógrafo eminente de Carlomagno. Se ha mencionado también a Gerungo, personaje prominente en la corte carolingia; a Frontario, obispo de Toul, conocido por sus habilidades como constructor; a Ansegio, abad de Fontanella; a Rábano M auro, abad de Fulda; a Regimberto, bibliotecario y director de la escuela monacal de Reichenau, y finalmente a H eito ( $†$ 836), obispo de Basilea de 803 a 823 y abad de Reichenau de 806 hasta su retiro en $823 .{ }^{4}$

Los autores Horn y Born, en su obra monumental sobre el Plano de Sankt Gallen, han hecho notar que la dedicatoria deja cuatro puntos bien definidos, a saber:

-Q ue quien elaboró el documento contaba con una especie de prototipo, del cual sacó una copia.

-Q ue el Plano es más bien un programa de necesidades, pues permitirá que el abad Gozberto use su habilidad al emplearlo.

-Q ue Gozberto mismo debió solicitarlo y por eso el remitente expresa que no quiere que se le considere lento.

-Q ue el autor y remitente del Plano es alguien de más alto rango que el abad Gozberto, por lo cual puede tratarlo de queridísimo hijo, lo cual sería impropio si fuera su superior o su igual. 5

3. H e tomado la versión latina paleografiada que publicaron Walter $\mathrm{H}$ orn y Ernest Born (The Plan of St. Gall, Berkeley, U niversity of California Press, 3 vols., 1979, vol. I, p. 9), en la que solamente he desatado las abreviaturas; sin embargo, no tomé su traducción por conside rarla demasiado libre. D oy mi propia versión, tratando de expresar, lo más fielmente posible, su sentido y forma originales.

4. Walter H orn y Ernest Born, op. cit., vol. I, p. II.

5. Ibidem, p. 9. 
La atribución al obispo-abad H eito ha quedado fundamentada razonablemente, al demostrarse que el plano fue elaborado precisamente en el scriptorium de la abadía de Reichenau, con la probable intervención de Regimberto y a través de dos amanuenses: uno joven, el principal, cuya escritura es compacta y clara, y otro mayor de edad que podría ser el mismo Regimberto, cuya escritura es más espaciada, pero que es el erudito que resolvió las anotaciones que requerían conocimientos especiales. ${ }^{6}$

Al aparecer en 1979 la extraordinaria obra en tres grandes tomos de $\mathrm{H}$ orn y Born, con los resultados de sus investigaciones realizadas durante unos veinte años, parecía que ya todo quedaba dicho, planteado, analizado y discutido sobre el Plano de Sankt Gallen. La obra, de verdad, es monumental y extraordinaria en su minuciosidad, pesquisas y conclusiones. Sin embargo, contra lo que podría haberse esperado, de inmediato, los descubrimientos, las hipótesis y las objeciones continuaron y se multiplicaron.

He aquí al gunos ejemplos de los temas de discusión que surgieron. La dedicatoria expresamente menciona que es una copia (exemplata direxi), pero ésta supone la necesidad de otro plano preexistente que ha servido de modelo. Al respecto, $\mathrm{H}$ orn y Born están convencidos de que se puede calcar un plano, con todo detalle, colocando una hoja de pergamino sobre otra. O pinan los mencionados autores que así se hizo y que por tal razón el dibujo es limpio, directo y "a mano alzada", es decir, a pulso, sin utilizar croquis previo ni instrumentos de trazo, como regla y compás. Sin embargo, cualquier arquitecto con experiencia de taller anterior al uso de computadoras podría haberles explicado que tal manera de calcar un plano es imposible.

Además, nuevos exámenes del Plano original, realizados por $\mathrm{N}$ orbert Stachura bajo luz ultravioleta, han demostrado que - contra lo que afirman H orn y Born - abundan los trazos previos hechos con "punta seca", algunos entintados y otros no.7 Se revelaron también ensayos de trazos de compás, con la perforación de su centro, dato que también pasaron por alto $\mathrm{H}$ orn y Born. En la zona de ambos ábsides del templo, hay varios ensayos de soluciones, con muy variados trazos de compás.

6. Bernhard Bischoff, Studien zum St. Gallen K losterplan, Sankt G allen, H istorischer Verein des Kantons St. Gallen, 1966, pp. 4I-49.

7. N orbert Stachura, "D er Plan von St. G allen - ein O riginal?", en Architectura 8, 1978, pp. I84-I86. 


\section{CARLOS CHANFÓN OLMOS}

Lo anterior, para muchos, resulta una contradicción que elimina el concepto de copia, pues es evidente que el dibujante, o su jefe directo, estuvieron haciendo u ordenando sucesivos ensayos de solución que alargaron las dimensiones del templo conventual. Nos parece que no hay tal contradicción. Basta que quien está ordenando o elaborando la copia sea el creador del prototipo que se está copiando. Todo arquitecto con experiencia sabe que, en todo momento, antes y durante el proceso de ejecución de una obra, pueden idearse mejoras que sería tonto no introducir. Además, tales tanteos en el Plano de Sankt Gallen sólo se refieren a la solución de los ábsides del templo, que con el claustro forman lo que llamaremos núcleo básico, característico del monasterio y esencial en la vida diaria del monje medieval.

Es este núcleo básico de templo-claustro el que está relacionado con los espacios monacales creados en la N ueva España como parte importante de la gran campaña de evangelización realizada por monjes mendicantes durante el siglo xvi. En efecto, es en los monasterios mendicantes y las actividades a ellos ancladas donde culmina la labor de los predicadores.

Preocupó mucho a H orn y Born la falta de precisión en las notas referentes a medidas. Pero, en cuanto a la precisión geométrica gráfica, olvidaron que el pergamino, sujeto a cambios de temperatura y humedad, sufre contracciones fuertes, que lo "arrugan". Estas alteraciones sólo pueden evitarse manteniendo el documento en un medio ambiente técnicamente controlado, con variaciones mínimas de calor y humedad, en una forma imposible de lograr en la Edad M edia.

Pero hay algo más, en cuanto a la precisión numérica, en las anotaciones explicativas. Recordemos el hecho señalado por Jean Gimpel para las cuentas en los registros de pago de impuestos y en las listas de raya semanales de las obras de las catedrales góticas a finales del siglo xiii. D ebido al uso generalizado de la numeración romana, la aritmética no había podido desarrollarse y era imposible realizar, con números romanos, operaciones de multiplicación y división. Aun las sumas y restas mayores a diez - los dedos de las manosestaban sujetas a múltiples errores, que han quedado testimoniados en los documentos de la época. D ice Gimpel al respecto:

La lista [de impuestos] está plagada de errores, que hoy no haría un chico de me nos de diez años, y no cabe sospechar ningún fraude, pues los errores son ya en más, ya en menos. Esta falta de precisión, que parece caracterizar al hombre me dieval y que vuelve a encontrarse en la construcción, parece chocante a nuestro 
espíritu moderno, ávido de minucia, de cifras y de estadísticas. Este defecto está en gran medida compensado por el espíritu de síntesis que animó a esta época. 8

Por semejante obstáculo de orden cultural, toda subdivisión o multiplicación debía hacerse por métodos geométricos gráficos, que - desde luego- no eran decimales. Así pues, en el Plano, los módulos de 40 X 40 pies, divididos correctamente en forma gráfica, no lo están en las anotaciones manuscritas que señalan dos veces seis, en lugar de dos veces veinte. En las circunstancias del momento histórico carolingio, tal error no es grave sino explicable y muy habitual. Tal obstáculo se prolongó por centurias, hasta principios del siglo xiii, en que se inició, con gran lentitud, primero el conocimiento y después el uso de la numeración arábiga, gracias a Leonardo Pisano, apodado Fibonacci (ca. II80-ca. I250). ${ }^{9}$

Así pues, nos parece que no hay objeción seria al carácter de copia del Plano de Sankt Gallen. Pero hay otros múltiples temas interesantes que pueden surgir de tan valioso documento. Q uizá lo más importante es todo lo referente a la arquitectura. No cabe duda de que el Plano es esencialmente un documento de arquitectura y que nos resulta especialmente importante por estar relacionado con la construcción monacal novohispana del siglo xvi, como explicaremos más adelante.

$\mathrm{H}$ orn y Born parecen convencidos, pues así lo afirman, de que no se trata de un proyecto ejecutivo, listo para ser construido en un terreno real. ${ }^{\text {Io }} \mathrm{Sin}$ embargo, delatan una idea incompleta sobre la verdadera naturaleza del Plano, al analizar una maqueta del siglo xix y ordenar la construcción de otra, a escala, del conjunto, para ser exhibida en el U niversity Art M useum de Berkeley, ${ }_{1}$ I lo cual resulta contradictorio con relación a la idea inicial de que no es un proyecto para ser construido.

¿Cómo comprender, entonces, lo que el Plano trata de comunicar? N os parece claro que, explicado en términos contemporáneos, se trata del progra-

8. Jean Gimpel, Los constructores de catedrales, Buenos Aires, Centro Editor de América Latina, I971, pp. 64-65.

9. En I2O2 apareció el libro Liber abaci, escrito por Fibonacci tras un largo viaje por España, África y el 0 riente, donde se reportaban los sistemas y métodos usados en la India y en el Islam. Así se despertó primero el interés, y después la adopción de la numeración arábiga, pero con la lentitud propia de la Edad M edia, todavía carente de imprenta.

Io. W alter H orn y Ernest Born, op. cit., t. I, p. 20.

II. Ibidem, vol. III, p. 245 . 
DOI: http://dx.doi.org/10.22201/iie.18703062e.2001.78.2007

58

CARLOS CHANFÓN OLMOS

ma arquitectónico de un conjunto monacal, expresado en una forma, ciertamente muy original, medieval. Ahí están las necesidades que debe satisfacer el monasterio - no listadas, como lo haríamos ahora, sino en un croquis gráfico que muestra la dependencia de unos locales con relación a otros. Es decir, se trata de un programa de necesidades pero, al mismo tiempo, de una guía gráfica de funcionamiento - una especie de organigrama - , todo en un mismo esquema. No tiene pues utilidad alguna la construcción de una maqueta.

La razón de la elaboración de un prototipo y de una copia viene al caso ante el cambio en el modo de vida que se está introduciendo en los monasterios, y ha sido ya discutido en dos sínodos. Los cambios discutidos y acordados requieren de un nuevo grado de habitabilidad en los espacios monacales que, por lo visto, no se logra plenamente en los espacios anteriores tradicionales.

Pero lo que se ha discutido y acordado en los sínodos son acciones que afectan la vida diaria y, en consecuencia, no son formas arquitectónicas fijas lo que se está buscando. Por lo tanto, caben los intentos de mejorar los espacios en busca de un partido arquitectónico ideal, que queda sujeto a la búsqueda de todos los abades y autoridades involucradas y a las experiencias obtenidas con las nuevas soluciones.

El examen detallado del plano nos muestra la diferencia entre el el emento característico - el núcleo básico templo-claustro- y las partes complementarias. En términos generales, es el núcleo característico el que está detallado con espesores de muros y distribución esquemática de mobiliario. Este núcleo es el que se acerca más al partido arquitectónico construible.

Por lo que toca a las partes complementarias, vemos que pueden ser identificadas porque, en general, no tienen espesores de muros, sino líneas que delimitan sus áreas. $\mathrm{H}$ emos pues hecho una subdivisión de áreas, para explicar las distintas funciones del conjunto conventual (figura 2).

El área i es el núcleo básico, elemento característico de todo monasterio; las reformas discutidas se refieren a las acciones diarias que ahí realizan los monjes. El área 2 está dedicada a una prolongación temporal de la vida religiosa, que aloja a los enfermos y a los novicios; el novicio que es aceptado pasa a ser monje en el núcleo básico, y el enfermo que sana o muere abandona la enfermería. El área 3 aloja los elementos de contacto con el mundo exterior, a saber, la casa del abad, la escuela laica, la casa de huéspedes distinguidos con alojamiento separado para su séquito, y el local de peregrinos. El 


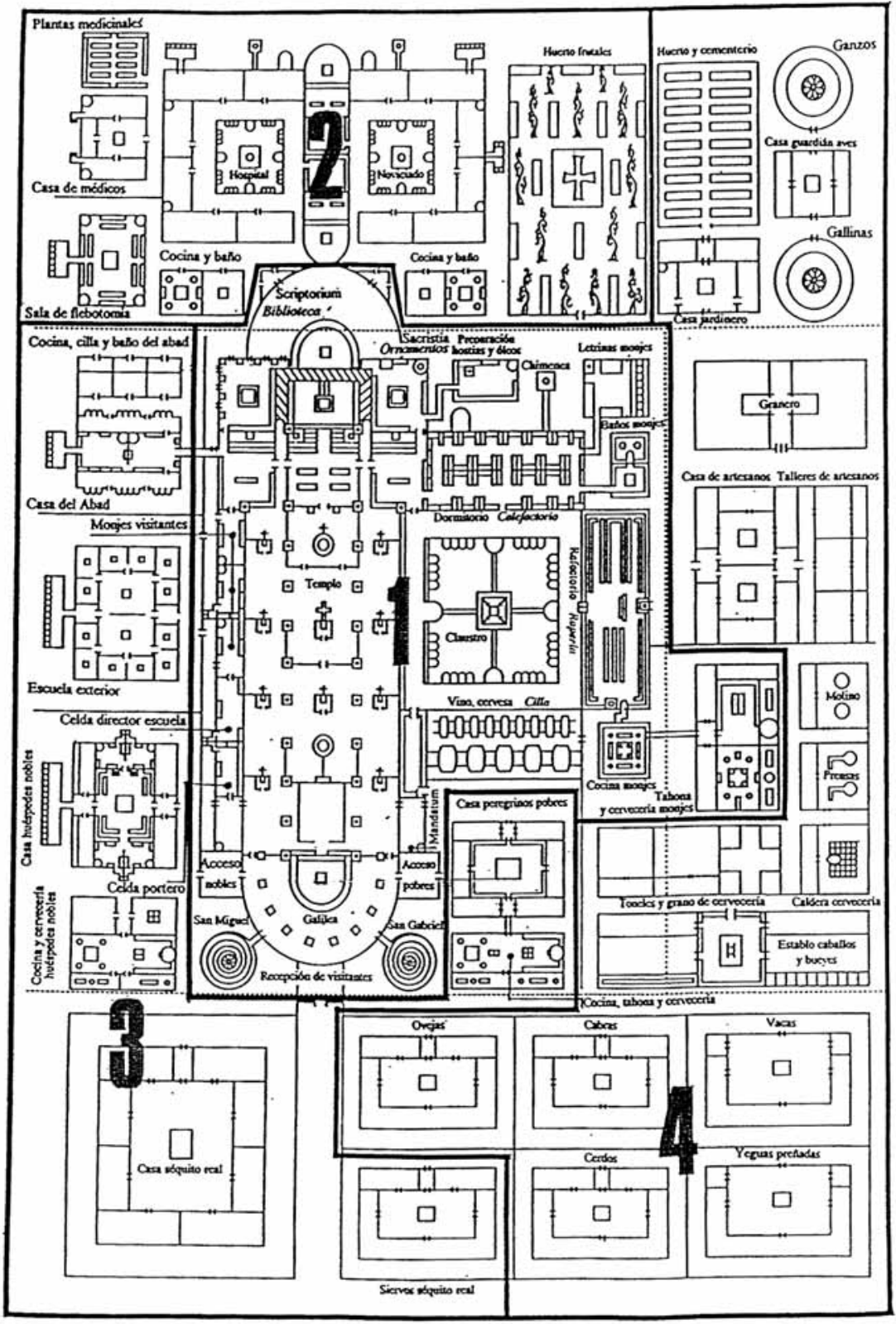

Figura 2. Áreas que integran el conjunto monacal en el Plano de Sankt Gallen. 
DOI: http://dx.doi.org/10.22201/iie.18703062e.2001.78.2007

60

CARLOS CHANFÓN OLMOS

área 4 es la que agrupa los elementos que garantizan la autosuficiencia del conjunto monacal: hortaliza, graneros, caballerizas, aves, porcinos, ovinos, bovinos y talleres de artesanos.

Todos los elementos del conjunto se agrupan acomodándose dentro de un rectángulo, que de ninguna manera sugiere o insinúa que así se construyan. Simplemente ocupan el espacio disponible en la hoja de pergamino, circunstancia que debió repetir lo sucedido en la elaboración del prototipo. Las cinco partes cosidas en el Plano de Sankt Gallen fueron así unidas para dar el área suficiente para reproducir el modelo previo, que tuvo que ser del mismo tamaño.

La importancia de cada el emento puede captarse en el grado de detalle en que está dibujado. No hay muro perimetral ni muralla circundante, porque no se trata de un terreno real. Por la misma razón, tampoco hay una puerta 0 acceso claramente indicados para acceder al conjunto. Por otro lado, en todos los monasterios conocidos, los distintos edificios se acomodan libremente con relación al núcleo principal, de acuerdo con la topografía, la dirección de los vientos y la disponibilidad del suministro de agua, etcétera, pero dejando generosos espacios entre los distintos el ementos.

En cuanto a la dependencia de unos locales con relación a otros, es muy digna de notarse la forma de expresar la relación necesaria. Se hace a través de dos líneas paral elas, que podrían interpretarse como una especie de sendero o caminito. No podrían ser ni túneles ni corredores o pasos a cubierto, desconocidos en la Edad M edia carolingia. Sólo que resulta absurdo un caminito que se quiebre en forma ortogonal, aun en muy pequeños tramos, cuando la forma obvia sería el trayecto recto esviajado, uniendo las dos puertas de los dos bloques involucrados, por la vía más corta. Véase la unión entre la cocina y el refectorio, o la del dormitorio con el baño y las letrinas, 0 la de la sacristía con el hostiario.

Este detalle de la expresión de dependencia entre locales con líneas acodadas ortogonalmente surge del dibujo que utiliza ejes principales ortogonales. H oy en día se logra con "regla T" y escuadras, y en la Edad M edia, con al gún otro procedimiento semejante. Además, nos parece que delata claramente la natural eza de esquema de funciones y no de plano ejecutivo del importante documento de Sankt Gallen. De hecho, en los casos reales de monasterios conocidos, ciertamente posteriores a la época carolingia por dos o tres centurias, la dependencia se resuelve adosando un local a otro, sin forzar a los usuarios a salir de uno para acceder al otro. 
O tro detalle interesante del dibujo es la deformación del ángulo inferior derecho del plano. Los espacios dedicados a las vacas y a las yeguas preñadas se escal onan en una forma rara, en lugar de al inearse con todos los elementos de ese extremo del conjunto, a saber: el establo, la caldera de la cervecería, las prensas, los molinos, los talleres de artesanos, etcétera. La razón nos parece obvia: la hoja de pergamino no da la medida completa. Se tiene ya un prototipo de un tamaño definido, que se debe copiar, y cambiar la escala es demasiado complicado y tardado, o bien se ignoran todavía los procedimientos para lograrlo. El dibujante, pues, hace una adaptación que no sale del espacio disponible. D ibujar los espacios para vacas y yeguas, incompletos, 0 alterando su forma rectangular, esviajando su extremo sur, no sería conveniente.

Con relación al núcleo básico, si observamos los pocos monasterios procedentes de la época carolingia de los cuales se tienen datos, observamos que los templos tienden a la forma cuadrada y no tienen el claustro adosado a uno de sus muros laterales. Gracias a las observaciones recientes de Werner Jacobsen, quien ha buscado la semejanza de soluciones carolingias a los distintos ensayos, observables bajo rayos ultravioleta en el Plano, ahora sabemos que antes de los sínodos de 8ı6 y 8ı7 sucedía lo siguiente en los monasterios:

- Las naves del templo, en número de tres, unidas, tenían la forma aproximada de un cuadrado.

-Contaban con uno o dos transeptos, el primero antecediendo al ábside, y otro posible a la entrada del templo.

-N o era común la posición del claustro adosado a un lado del templo.

- Los monasterios relacionados con Benito de Aniano muestran naves en forma más alargada con dos absidiolas además del ábside principal, pero sin el claustro adosado lateralmente.

Jacobsen ha mostrado que una de las soluciones desechadas en el Plano de Sankt Gallen incluía un transepto en el extremo occidental de la nave, pero fue borrado después de haber sido trazado y entintado. Al suprimir este transepto, la nave se alargó hasta dar la proporción de doble cuadrado.'22

El mismo investigador ha mostrado, con el apoyo de datos arqueológicos, que la iglesia de $\mathrm{H}$ eito, consagrada en $8 \mathrm{I} 6$, en Reichenau (figura 3 ), tenía tres naves que unidas no llegaban a la proporción de un cuadrado y que en la 
62

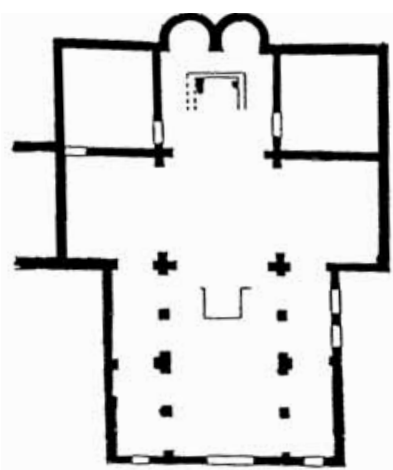

Figura 3. Templo abacial de Reichenau consagrado por H eito en 8I6, según W. J acobsen.
CARLOS CHANFÓN OLMOS

Figura 4. Templo abacial de Reichenau iniciado por Erlebaldo en 83o, según W. Jacobsen.

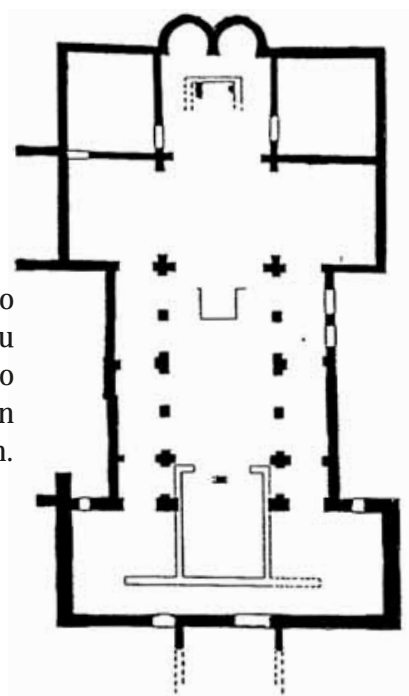

ampliación del abad Erlebaldo, iniciada en 830 (figura 4), se añadió un transepto occidental, con un pequeño aumento a las naves que les dio la proporción cuadrada.

Para completar sus observaciones, Jacobsen, también con apoyo arqueológico, ha mostrado que el templo abacial construido por G ozberto entre 830 y 835 (figura 5 ) tiene el conjunto de naves apenas mayor que un cuadrado y su ábside, único, no es semicircular. Por otro lado, iglesias abaciales ligadas a la influencia de san Benito de Aniano tienen la clara tendencia al alargamiento de las naves, transepto oriental y ábside semicircular con absidiolas de la misma forma rematando las naves laterales. Tal es el caso de Kornelimünster (8I5-8I7), M armoutier (8I4-8I5?), Steinbach (8I5-8I7) y - aunque sin ábside ni absidiolas- Argelliers (780-799) (figuras 6 a 9). En todos estos casos no hay claustro adosado lateralmente.

¿Todo lo anterior podría sugerir que la tendencia al conjunto de naves en proporción cuadrada habría constituido una especie de more germanico, mientras las naves al argadas representaban una característica de un cierto more latino, que Benito de Aniano en sus effuerzos de reforma trató de difundir? Es posible, y la explicación tendría que buscarse en el análisis de la Regla Benedictina y su ritual litúrgico, quizá ante la necesidad de abrir su templo y sus ceremonias al público laico. 


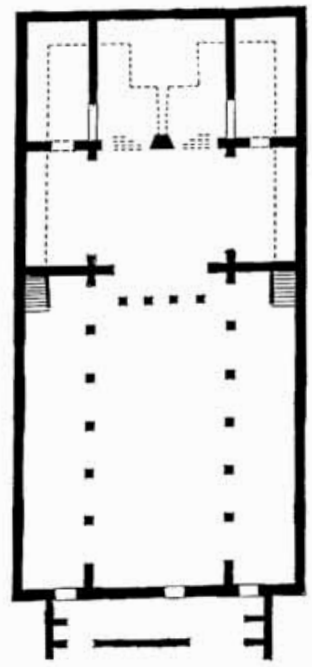

Figura 5. Templo abacial de Sankt Gallen construido por G ozberto entre 830-835, según W. Jacobsen.

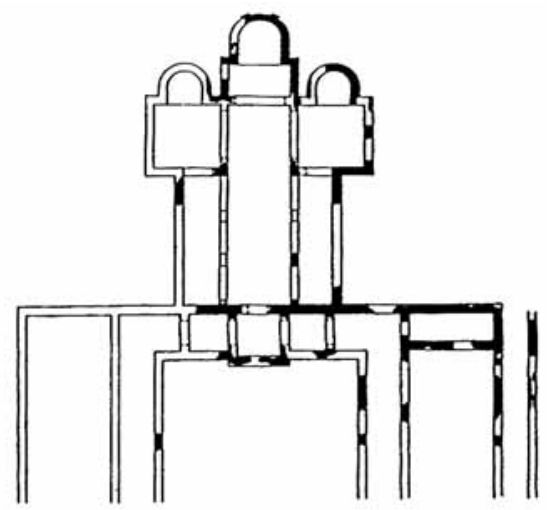

Figura 6. Templo abacial de Kornelimünster, de Benito de Aniano, según W. Jacobsen.

La verdad es que se cuenta con muy pocos datos sobre la arquitectura monacal carolingia como para poder apoyar con absoluta certeza las variadas hipótesis que podrían explicar las distintas opciones usadas en los conjuntos monásticos.

Sin olvidar tal debilidad argumentativa, podemos mencionar que, para el siglo viii, la migración de monjes ingleses e irlandeses, empujada por las invasiones nórdicas a territorio europeo, había dado continuidad a un monacato más inclinado a las costumbres contemplativas orientales ligadas al anacoretismo inicial, mientras que los monasterios del continente seguían los criterios de san Benito de N ursia, que indicaban al monje lo que debía hacer en cada minuto de su vida.

San Benito de Aniano vio la necesidad de unificar y reglamentar criterios monacales, sin duda para evitar abusos o prácticas objetables en las instituciones cenobíticas. El apoyo de asesores del monarca, como Alcuino y Eguinardo, debio de lograr la aprobación imperial. D e este modo se obligó a todos los monasterios del Imperio a adoptar la Regla de san Benito.

La solución de templo alargado y claustro lateral podría haberse originado en Montecasino, pero no hay suficientes datos arqueológicos que lo confirmen con seguridad, pues el monasterio fundado por san Benito (ca. 48o-ca. 553) hacia 529 fue destruido a finales del siglo por una invasión de longo- 
64

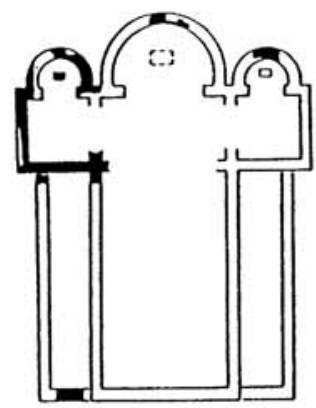

Figura 7. Templo abacial de M armoutier, de Benito de Aniano, según W. Jacobsen.
CARLOS CHANFÓN OLMOS

Figura 8. Templo abacial de Steinbach, de Eguinardo, según W. Jacobsen.

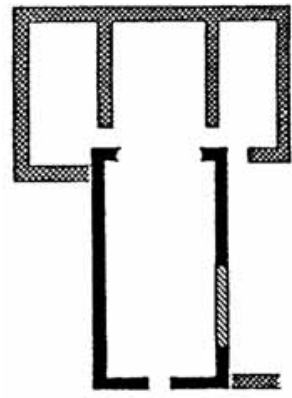

Figura 9. Templo abacial de Argelliers, de Benito de Aniano, según W. Jacobsen.

bardos. No fue hasta 720 cuando una pequeña comunidad se volvió a establecer ahí y creció lentamente gracias a los apoyos de monarcas carolingios.

Ya vimos que, en los pocos datos conocidos sobre monasterios germanos carolingios, aparecen las naves adoptando la forma cuadrada y sin claustro adosado lateralmente. Estas características coinciden con las soluciones orientales de monasterios conocidos como el monasterio de San Simón Estilita, en Antioquía (siglo v), el monasterio armenio de Sanahin (siglo $\mathrm{x}$ ), y el monasterio armenio de $\mathrm{H}$ aghbat (siglo xii) (figuras io a I2). Pero también existe otra semejanza importante, pues en unos y otros casos - los orientales y los carolingios- los conjuntos monacales están formados por edificios aislados que se acomodan convenientemente para formar grupos, dejando patios y espacios distributivos en las áreas intermedias.

La tendencia a asignar una sola función específica a cada edificio, más o menos integrado al conjunto, construido en madera, con muros bajos y grandes cubiertas a dos aguas, por lo menos hasta la época carolingia, contó con la preferencia de los pueblos germánicos. ¿Fue quizá porque tal disposición facilitaba el desalojo rápido de nieve y aguas pluviales, mientras que cualquier intersección de cuerpos de edificio la dificultaba? Es muy posible. En todo caso, tal modo de construir quitaba toda monumentalidad a los conjuntos monacales. Ese sistema constructivo, con madera y con 


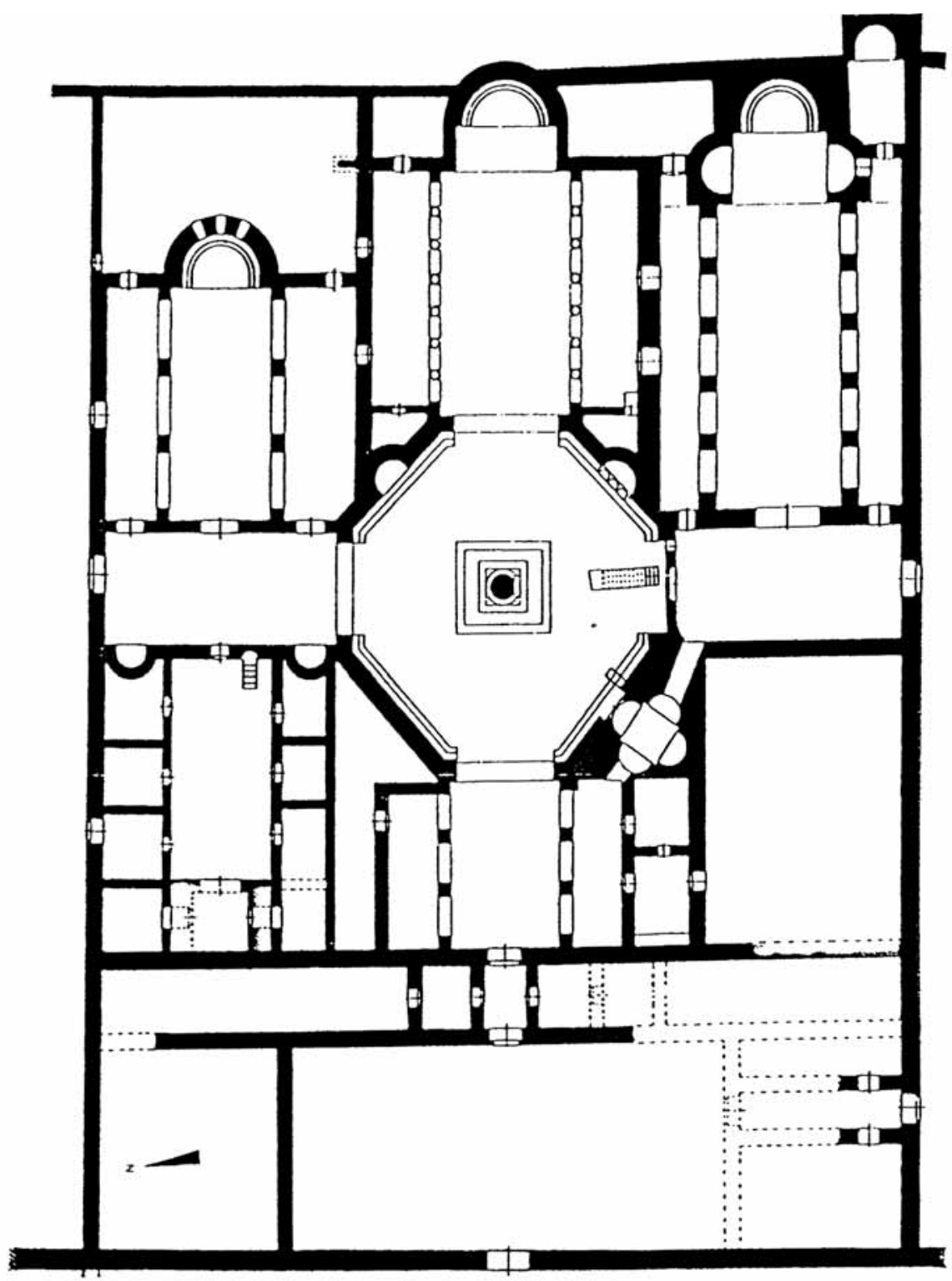

Figura ıo. M onasterio oriental de San Simón Estilita, Antioquía, siglo v, ajeno al esquema carolingio. 


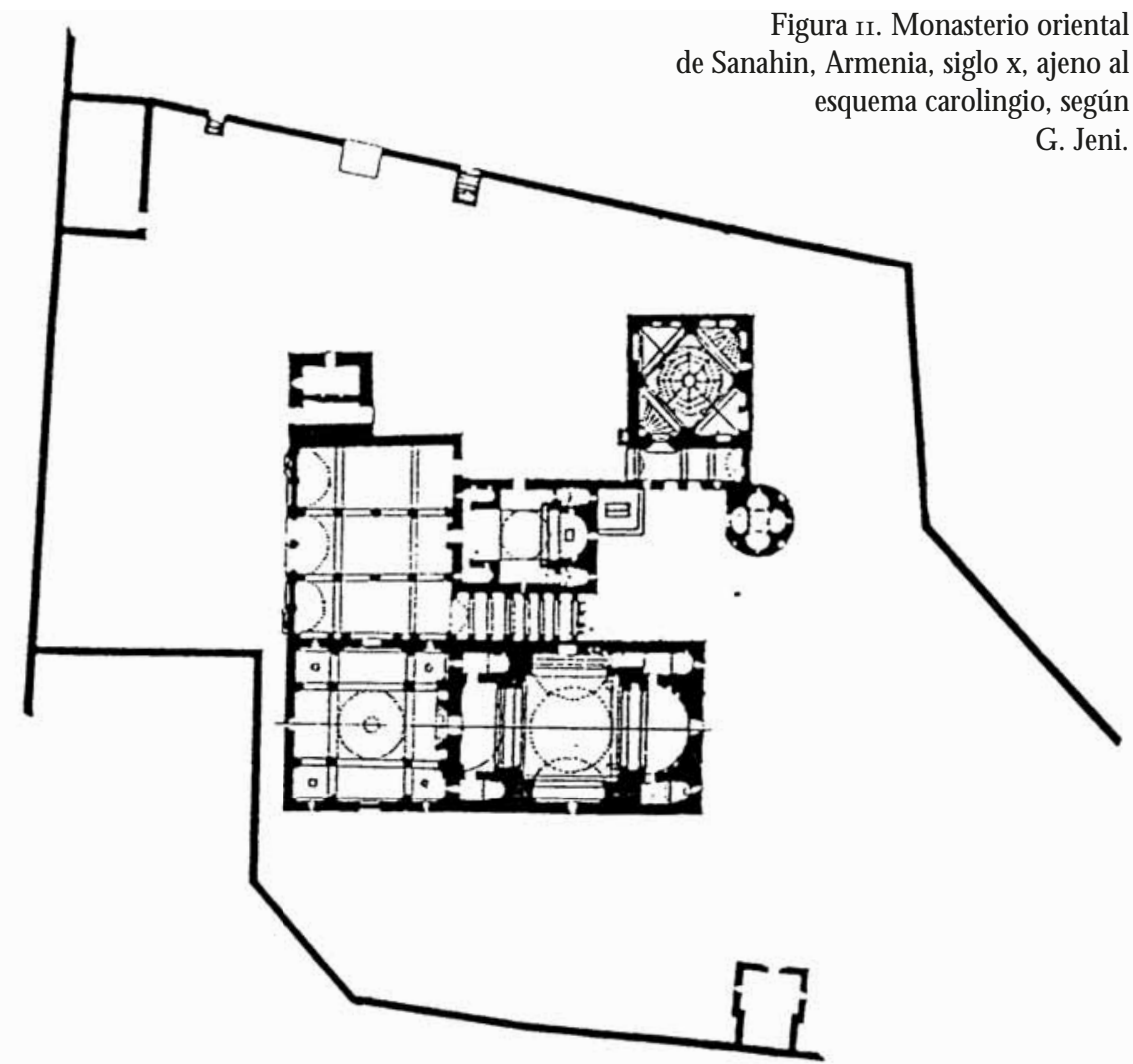

empinadas cubiertas a dos aguas, es el que se infiere del esquema de Sankt Gallen.

El claustro, en efecto, no es un patio dejado al centro de un gran edificio en forma de " $C$ " invertida, adosada al templo. El claustro se forma con tres edificios independientes, que se tocan en las esquinas y se adosan al templo, para formar el espacio abierto central. El claustro, sin embargo, cuenta con corredor perimetral cubierto, cuya techumbre tiene que ser la prolongación en forma de alero de las cubiertas de los cuatro edificios involucrados. N os parece que este detalle de los aleros para el corredor del claustro revela que el autor del plano pensó en las técnicas de construcción con madera.

Sin embargo, no podemos olvidar que, en el campo de la construcción, un logro notable del periodo carolingio fue la recuperación y difusión de las 
Figura I2. M onasterio oriental de $\mathrm{H}$ aghbat, Armenia, siglo xii, ajeno al esquema carolingio, según $\mathrm{G}$. Jeni.

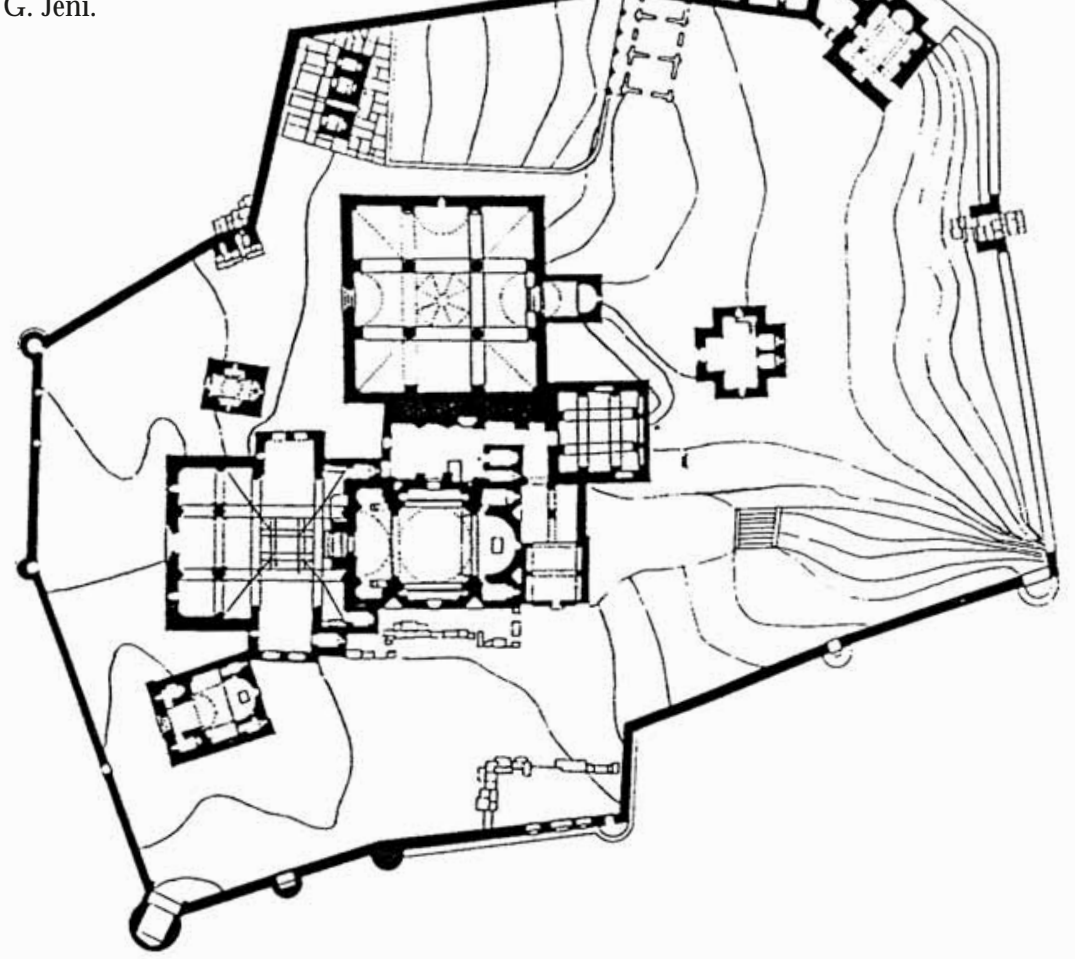

técnicas romanas para construir con piedra, desaparecidas del ámbito europeo desde la caída del Imperio Romano. Tal conjunto de procedimientos constructivos desde entonces - a un milenio de la aparición del concepto de estilo- recibió el nombre de romanico o more romanico, aludiendo a la técnica de la cantería, pero estableciendo la diferencia. En efecto, no se denominó romano, sino románico, para no confundir lo moderno de ese momento con lo procedente del Imperio Romano. No se piense, pues, que la denominación de románico aludía a todo un estilo arquitectónico, sino solamente a una técnica constructiva, la de la cantería labrada.

Pero vayamos al significado cultural del Plano. Las ruinas y documentos existentes, así como las investigaciones realizadas, indican que el núcleo elemental formado por el templo conventual de forma alargada, con el claustro 
DOI: http://dx.doi.org/10.22201/iie.18703062e.2001.78.2007

68

CARLOS CHANFÓN OLMOS

adosado a uno de sus lados, lentamente se impuso en el diseño de conjuntos monásticos. Este hecho indica que se adaptaba bien a las prácticas diarias de la vida cenobítica, creada y difundida por la Regla Benedictina.

Pronto, el centro geográfico, lleno de iniciativas que desde el primer tercio del siglo ix representó el núcleo creativo y de vanguardia helvético-franco-germánico, con sede en Basilea - al lado del lago de Constanza y del camino de Germania hacia Italia - , cedió el puesto a un nuevo centro de creatividad en el mundo monástico medieval. El nuevo foco de iniciativa impulsó a la institución monástica hasta alcanzar su máxima influencia en la creación del modo de vida genuinamente europeo, no solamente monacal, sino de todas las sociedades cristianas. D esde el siglo x la nueva vanguardia del monacato se situó en la Borgoña, de raigambre galo-romana y eminentemente céltica.

Prueba de ello son las múltiples reformas borgoñonas generadas en los siglos x a xii. Cluny, Cîteaux, Clairvaux y, en menor escala, la Grande-C hartreuse, la Grande-Trappe y Prémontré, impresionaron al mundo cristiano con su preparación intelectual, su práctica de la virtud, su brillante ceremonialismo litúrgico y sus monumentales conjuntos monacales.

Durante estos siglos, el núcleo básico de templo y claustro lateral guardó plena vigencia, cambiando solamente su expresión plástica, que evolucionó desde la monumentalidad cluniacense y la sobriedad románica hasta la extraordinaria espiritualidad expresada por el gótico.

Pero en los inicios del siglo xiii, con la O rden Benedictina en decadencia, el impulso de renovación descendió al M editerráneo. En el primer tercio del siglo aparecieron las órdenes mendicantes en España e Italia. Su creación, aunque no se le conoce como reforma, significó un cambio mucho más radical en la vida monacal que todas las reformas anteriores juntas.

El monje mendicante no vive en su convento, sino que su principal ocupación es instruir al gran pueblo cristiano por medio de la predicación. Para poder dar toda su atención a tal tarea, vive de limosna en extrema pobreza, de ahí el nombre de mendicante. Los monasterios mendicantes, por lo tanto, no son unidades autosuficientes alejadas de los núcleos urbanos, sino bases de operaciones que buscan ubicación en las principales ciudades, desde donde cubren amplios territorios en sus correrías misionales. Es por eso que sus monasterios no son independientes unos de otros, como los benedictinos, sino que se agrupan por regiones, bajo una estructura de autoridad en forma piramidal, buscando ubicaciones estratégicas desde donde organizar y distribuir con mayor eficiencia su trabajo misional. 
El nuevo modo de vida monacal mendicante exigió nuevas condiciones de habitabilidad, y es muy claro para el siglo xv que los conjuntos monacales de dominicos y franciscanos no cuentan con el templo y claustro adosado a un lado, en la disposición tradicional medieval. D esde entonces, en las instalaciones mendicantes existen múltiples patios porticados, pero que carecen de las tradicionales funciones medievales de claustro. $\mathrm{No}$ hay procesiones de los monjes por sus corredores, no existe en su recinto la ley de clausura y, en consecuencia, sus espacios no son exclusivos para el uso monacal, no impera en ellos la norma del silencio.

Ahora los conjuntos carecen de los elementos de autosuficiencia rural, cuentan con patios y locales para enseñanza y para atención de enfermos y peregrinos. El elemento característico, pues, dejó de ser el núcleo básico tradicional medieval. En su lugar surgió el conjunto de celdas individuales en un conjunto próximo al templo conventual. La formación intelectual personal y la preparación de la predicación encontraron en la celda individual su espacio propicio para la concentración y el estudio. Ahí, en las celdas, es donde se mantienen la ley de clausura y la norma del silencio.

Pero la predicación requiere de amplios conocimientos, y los mendicantes pronto dieron pruebas de poseerlos. D esde el mismo siglo xiii, los grandes profesores de las universidades fueron los miembros de las órdenes mendicantes. Alberto M agno (I193-I280) y Tomás de Aquino (I225-I274) fueron dominicos, D uns Scott (I27O-I308) y san Buenaventura (I22I-I274) fueron franciscanos.

Pronto, a finales del siglo xv y principios del xvi, surge en el panorama mundial un nuevo escenario, el $\mathrm{N}$ uevo $\mathrm{M}$ undo, con tremendos retos, pero extraordinariamente adaptado a los ideales mendicantes, que ni los mismos fundadores, D omingo de Guzmán o Francisco de Asís, hubieran imaginado. En Europa, los mendicantes se enfrentaban a un pueblo cristiano, o que conocía el cristianismo - como fue el caso de los musulmanes españoles- y que hablaba su misma lengua. En el N uevo M undo, la población no tenía la menor idea de la religión católica, y los monjes mendicantes no hablaban las lenguas autóctonas. El primer gran escenario fue la N ueva España, donde se realizó la primera gran campaña de evangelización mendicante.

Aquí es donde aparece la relación entre N ueva España y la solución carolingia de templo y claustro lateral. Aunque ya abandonada en Europa, esta solución reaparece en nuestro territorio, desde los primeros casos de construcción de monasterios. 


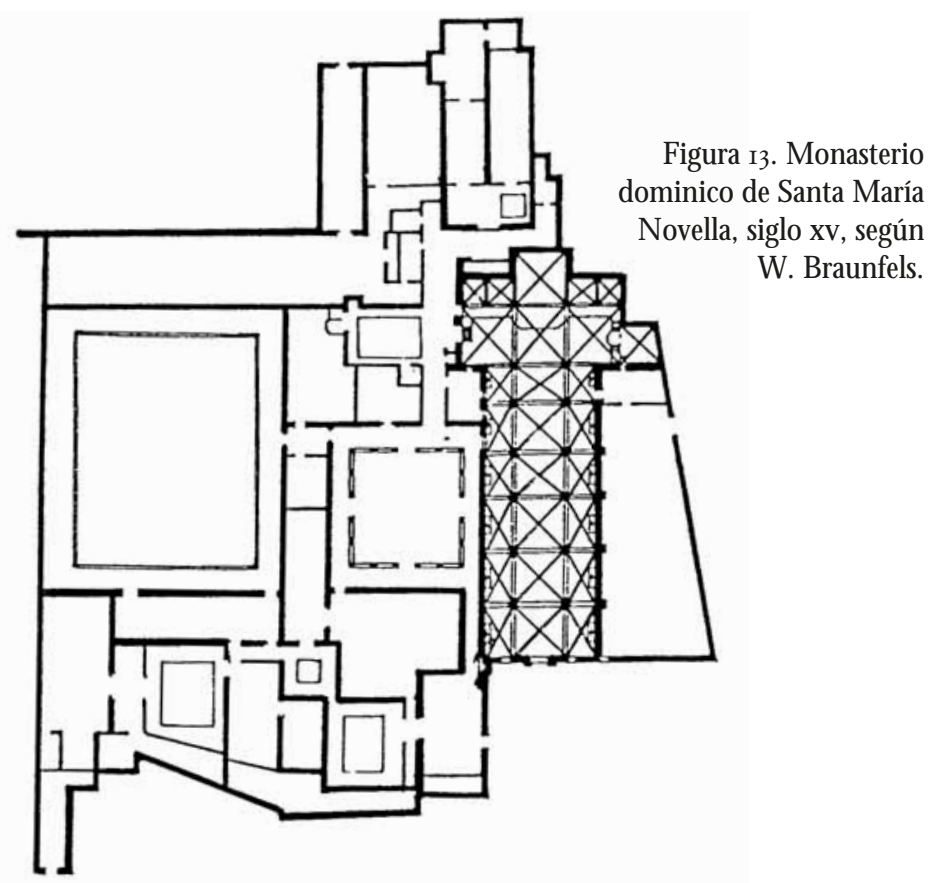

No es éste el lugar para analizar las circunstancias de la gran campaña y evaluar las causas de su éxito fulgurante en los principales grupos étnicos del país. El problema que aquí se nos plantea es dilucidar las causas que pudieron respaldar esta recuperación de una solución arquitectónica que sin duda en Europa se consideraba ya anacrónica o poco funcional. Sin una amplia investigación, profunda y completa, no será posible llegar a conclusiones convincentes. Pero tal investigación no se ha hecho.

A lo más que podemos llegar por ahora es al planteamiento de ideas que podrían dar inicio a programas de investigación. Pero no olvidemos que una cosa es suponer que los hechos pasados pudieron ser así, y otra muy distinta es el demostrar que así fueron.

$\mathrm{H}$ echa la advertencia, reconstruyamos un poco el modo de vida inicial y los ideales de los mendicantes. D omingo de Guzmán y, sobre todo, Francisco de Asís mostraron una clara despreocupación por la posesión de inmuebles. Según su Regla, los franciscanos no podían poseer monasterios. De todas 
maneras, en sus correrías misionales por las aldeas más remotas, muy a menudo no podían regresar a su base de operaciones durante varias jornadas. ¿D ónde, pues, pasaban la noche y se alimentaban?

Es de suponerse que los predicadores mendicantes eran alojados por el clero secular, al que apoyaban con su trabajo, en las parroquias en las que misionaban. Pero durante las jornadas de viaje, a veces de varios días, caminando, debían pernoctar en los monasterios de las órdenes antiguas. Recordemos que ya en el Plano de Sankt Gallen hay lugar especial para alojar a monjes peregrinos.

Así pues, nos parece que todo mendicante europeo conocía bien la vida interior de los monasterios, por haberse alojado en ellos en múltiples ocasiones, y en consecuencia apreciaba las condiciones que encontraba para descansar, para estudiar, para rezar y asistir a las ceremonias litúrgicas, etcétera.

Al iniciarse la gran campaña misional en la N ueva España, la orden franciscana no contaba aún con un modelo funcional de convento mendicante. Las reformas impuestas por el cardenal Cisneros eran muy recientes y no había habido tiempo de crear una experiencia. ¿Fue pues, quizá, tal ausencia de un prototipo funcional mendicante lo que inclinó a los monjes a adoptar la solución antigua, conocida y apreciada? Es posible.

Por otro lado, los conventos mendicantes proliferaron en pequeñas poblaciones, y solamente en forma limitada se volvieron base de operaciones, salvo en las grandes ciudades novohispanas. En efecto, estos primeros monasterios tuvieron que ser unidades autosuficientes, sede de los servicios parroquiales para las poblaciones.

La evangelización devolvió a las comunidades indígenas una estructura de vida que la Conquista había destruido sin contemplaciones. E ra pues necesario dar autosuficiencia a estas comunidades eminentemente agrícolas, con requerimiento de servicios tanto públicos como religiosos, en especial de educación. El monasterio fue la sede de tal estructura, tanto en el aspecto civil como religioso.

Los mendicantes llegaron a predicar en un país pagano y carente de clero secular; por lo tanto, una vez cristianizadas las comunidades indígenas, los monjes tuvieron que asumir las tareas del clero secular hasta que éste naciera, se desarrollara y ejerciera sus responsabilidades. Entre tanto, solamente los monjes podían suplirlo. Para el indígena, la iglesia conventual era su templo parroquial. Para el monje, su monasterio era base de las operaciones de servicios locales, en su área parroquial. 


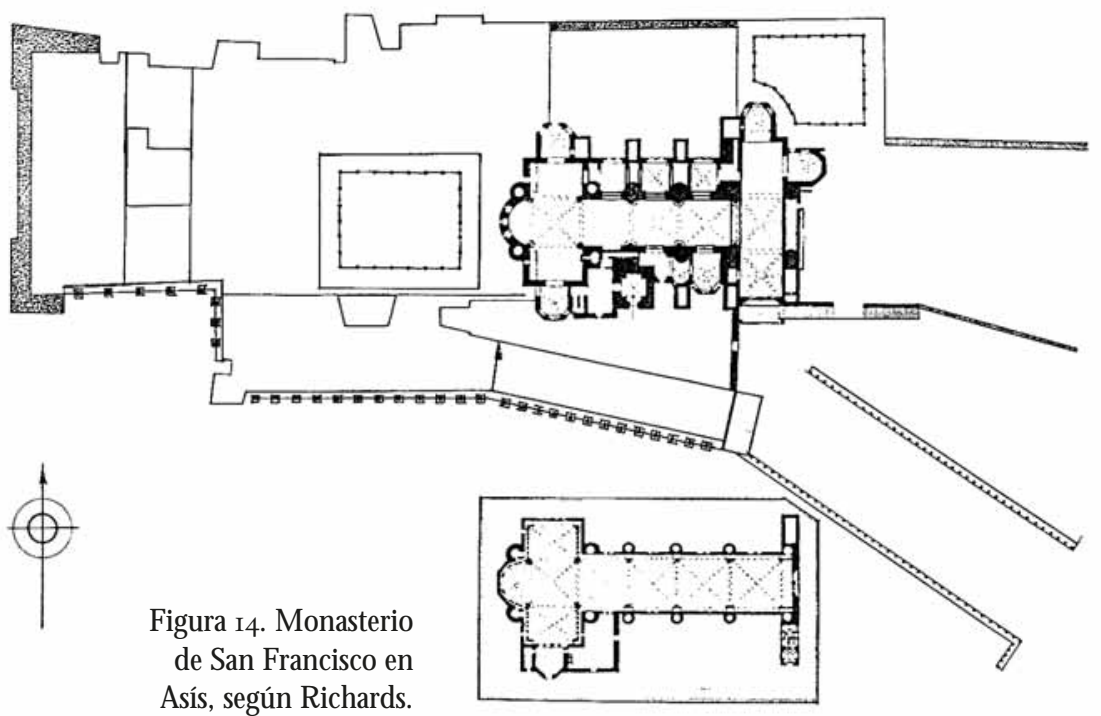

Esta autosuficiencia, circunstancialmente impuesta al monasterio, hizo que volviera a tener huerto de grandes dimensiones, con cuyo producto se ayudaba a dar alimento a los grupos de adolescentes que apoyaban a los predicadores en sus correrías misionales y que trabajaban al derredor de los monasterios en una gran multitud de tareas diarias.

¿Fue entonces esta autosuficiencia, en al guna forma semejante a la de las grandes instituciones medievales, la que llevó a la adopción del núcleo básico carolingio, dando así a los monjes un espacio específico para cumplir los ideales de la vida monástica - de estudio, meditación y silencio- ante el tremendo cúmulo de nuevas obligaciones que se apilaron sobre sus hombros, en especial las relacionadas con la educación de los niños y jóvenes indígenas? Es probable.

En todo caso, este regreso al núcleo básico carolingio en la N ueva España, unos dos siglos después de su abandono en Europa, fue fugaz, ya que apenas duró un medio siglo. Las circunstancias políticas cambiaron a la muerte de Carlos V. A las visiones humanistas de M oro y Erasmo, que inspiraban al emperador, siguió la búsqueda de Felipe II de los ideales del Príncipe de M aquiavelo. M ientras, las grandes epidemias diezmaron repetidas veces a la po- 
blación indígena, a la vez que el interés oficial en la educación del indígena desaparecía y las autoridades civiles y religiosas centraban sus esfuerzos en los grandes colegios para españoles y criollos.

Por otro lado, avanzado ya el desarrollo del clero secular, que los ordenamientos del C oncilio de Trento habían retardado - al exigir una larga preparación para los sacerdotes-, se inició muy lentamente la entrega de parroquias en manos de los monjes a los párrocos seglares. Todos estos cambios, desde principios del siglo xvii, iniciaron el retorno de los monjes mendicantes a sus tareas habituales en un país católico, apoyando a la estructura secular, responsable directa de los servicios religiosos y la instrucción de los fieles.

El trabajo misional, sin embargo, no desapareció, sino que cambió de rumbo para dedicar sus esfuerzos a las áreas semidesérticas de Aridoamérica, pobladas de pequeños aunque muy numerosos grupos nómadas o seminómadas. Estos nuevos frentes de trabajo requerían de otras estrategias y otras estructuras, donde no cabían los monasterios del tipo construido en el Altiplano Central.

\section{Epílogo}

Fue así como nuestros monasterios mendicantes del siglo Xvı pudieron en alguna forma heredar y hacer arquitectónicamente patente la gran herencia monástica medieval, fuente de desarrollo y progreso en aspectos tan disímbolos como la arquitectura y el conocimiento teórico para la vieja Europa. $\mathrm{H}$ ay pues un interesante hilo de continuidad entre el monacato medieval y la evangelización renacentista novohispana, que se expresa en términos arquitectónicos.

Si bien la Europa del protorrenacimiento había ya desechado el núcleo básico carolingio, eran todavía muchos los monasterios antiguos que lo utilizaban en aceptable armonía con sus funciones. Fue quizá el periodo barroco el que creó una nueva arquitectura monástica, más adaptada a los requerimientos de la modernidad del momento para las órdenes antiguas subsistentes. Para entenderlo, no podemos olvidar la necesaria relación entre las funciones claustrales y las exigencias de la sociedad civil de cada momento de la historia medieval, renacentista o barroca.

Pero el núcleo básico carolingio no vino a morir en los conventos mexicanos del siglo xvi. La labor misional mendicante debía aún concederle una úl- 
DOI: http://dx.doi.org/10.22201/iie.18703062e.2001.78.2007

tima manifestación arquitectónica durante el siglo xviii, al repetirse los antiguos requerimientos de autosuficiencia en las poblaciones incluidas en la campaña de evangelización. Este canto del cisne del templo conventual y su claustro lateral vieron una última expresión en las cinco misiones tardías de la Sierra Gorda queretana, que logró la conversión de los indígenas pames en un medio geográfico agreste e incomunicado.

Los primeros misioneros franciscanos de esta zona salieron del Colegio de Propaganda Fide de San Fernando de M éxico a continuar una labor ya iniciada antes por agustinos y dominicos, pero con poco éxito y muchas dificultades, que los obligaron a retirarse. Tras este segundo intento, al lograr finalmente la conversión, con la ayuda de indígenas tlaxcaltecas y otomíes ya cristianizados, fray Pedro Pérez de M ezquía, con apoyo del teniente capitán general don José de Escandón, inició hacia i744 la construcción de capillas y chozas provisionales para los monjes.

Sin embargo, no fue hasta I75I, a la llegada del franciscano fray Junípero Serra, cuando se iniciaron los trabajos de construcción definitiva de los cinco monasterios franciscanos de la Sierra Gorda, cuyos nombres originales son M isión del Señor Santiago de Jalpa, M isión de la Purísima Concepción de Landa, M isión de San M iguel de Concá, M isión de San Francisco de Tilaco y M isión de N uestra Señora de la Luz de Tancoyol.

Se trata de cinco pequeñas poblaciones que, por su situación geográfica, son de muy difícil acceso, aún hoy día, pese a que ya cuentan con una buena carretera pavimentada. A finales del siglo xviii, era pues importante garantizar su autosuficiencia y la prestación de los servicios religiosos y civiles que requerían.

Los cinco monasterios son de reducidas dimensiones pero con el partido arquitectónico que hemos Ilamado núcleo básico carolingio. Su construcción se realizó en el tercer cuarto del siglo xviii y en ella participaron los habitantes del lugar, con la dirección de oficiales y maestros indígenas ya bautizados, traídos de las zonas bajo control franciscano, como T laxcala, Q uerétaro, Zacatecas y la capital del virreinato.

Para entonces, este núcleo básico carolingio, difundido desde las orillas del lago de Constanza a todo el ámbito europeo, completaba ya más de un milenio de vida y todavía encontraba escenarios para mostrar su utilidad en un $\mathrm{N}$ uevo M undo lleno de juventud.

Aquí pues vino a terminar sus días la solución carolingia, que adquirió dimensiones monumentales y fue testigo de los momentos más gloriosos del 
DOI: http://dx.doi.org/10.22201/iie.18703062e.2001.78.2007

monacato medieval. En su última expresión mexicana, llegó a su fin con enorme dignidad, también monumental, no tanto por sus dimensiones, ciertamente modestas, sino más bien por su extraordinaria calidad arquitectónica.

C oyoacán, 22 de septiembre de 200 . \$ 